\title{
The Relationship Between Exchage Rates and Inflation: The Case of Iran
}

\author{
By Sanam Shojaeipour Monfared ${ }^{1}$, Fetullah Akin ${ }^{2}$
}

\begin{abstract}
Iran is a country, which has experienced high, and chronic inflation period and fluctuating Exchange rates during past decades. After the revolution in Iran in 1979, followed by eight-year Iran-Iraq war and world oil crises, high inflation has been one of the Iran's most important problems. Especially during past years boycotts against trade caused instable Exchange rates and high inflation in Iran. These issues attract economists' interest toward this subject. Therefore, the aim of this study is to analyze the relationship between Exchange rate and inflation based on time series data, using Hendry General to Specific Modeling method and Vector Autoregression (VAR) model. To this end, we used annual data for the period 1976-2012 for Hendry method. We also used the quarterly data between 1997: 3 - 2011: 4 to estimate VAR model. Due to economic instability in recent years and lack of valid data we estimated model up to 2012. As a result of the Hendry model, it is obtained that there is a direct relationship between Exchange rate and inflation. An increase in foreign exchange rates makes the inflation goes up. By including the money supply variable to VAR model the effects of money supply and the exchange rate on inflation has been investigated as well. According to the results, both the money supply and the exchange rate affect the inflation in the positive direction. Contribution of the money supply on inflation is greater than the exchange rate.
\end{abstract}

\section{Keywords: Exchange Rate, inflation, Hendry Method, Time Series, VAR model}

\section{Introduction}

The inflation and exchange rate relationship has always been one of the fascinating topics for economists (Svensson, 1987). The exchange rate-inflation relationship has a vital importance, especially in emerging economies. In these economies, exchange rate fluctuations can significantly affect the general level of the prices (Dornbuch, 1976). According to Dornbuch when the exchange rate defined as the rate of change between two national currencies, increases will be exist in the overall level of prices. Then when the exchange rate falls, that is, when the domestic currency appreciates, prices are expected to fall in the general level. A change in exchange rates will affect production costs as imported goods prices which will be changed as well exchange rates. For this reason, it is possible to say that there is a very close relationship between the exchange rate and inflation. Therefore, in developing countries, it is necessary to implement real exchange rate policies to take domestic inflation into account in to maintain stability in national production and international competition without falling into the foreign exchange bottleneck. So with respect to this fact there is a need to conduct research on the exchange rate-inflation relationship.

As a country that is constantly facing crises, Iran is experiencing high and chronic inflation. In the Iranian economy, the Islamic Republic revolution of 1979 followed by the eight-year Iran-Iraq war, world oil crises have been the factors that triggered the high 
inflation rate. Especially in recent years, the US economic sanctions and obstacles to oil exports have been caused significant problems in the economy for a petroleumdependent country like Iran. It also caused excessive fluctuations in the exchange rate and excessive depreciation of the Iranian currency (Reference). Therefore, the main purpose of the study is to test the effect of exchange rate changes on Iran inflation on theoretical and empirical examination of Iran.

\section{Relationship between Exchange Rate and Inflation}

\subsection{Theoretical Framework}

The relationship between exchange rate and inflation is explained by Dornbusch (1987) for the first time. According him it developed an econometric model and examined the effect of the exchange rate on prices. Dornbusch 's work has been the basis for other works (Kasapoğlu, 2007; Brooks, 2002). When examining the relationship between exchange rate and domestic prices, Dornbusch talked about market density, import volume, import substitute and domestic production channels.

Agenor and Montiel (1996) mentioned four major transmission mechanisms of how exchange rate fluctuations affect inflation:

- An open economy can directly affects the price of imported substitute goods and goods subject to trade.

- It can indirectly increase the price of the final goods through imported input prices.

- Due to fluctuations in the exchange rate, the uncertainties in foreign currency prices can affect domestic price makers and increase domestic prices.

- Finally, it increases the prices by the means of wages.

According to Svensson (2000) one of the role of the exchange rate in the monetary transmission mechanism. Accordingly, the exchange rate changes can affect the inflation rate through three different channels:

- The exchange rate changes experienced in an open economy affects the relative prices between domestic and foreign goods, so caused domestic and foreign demand to domestic goods. As a result, total demand and indirect inflation rate are affected by net exports.

- On the other hand the changes in the exchange rate directly affect the prices of the imported final goods in terms of national currencies. Consequently it directly affects the consumer prices index. Ultimately, the inflation rate is affected by the prices of imported final goods, and this effect is usually realized in a shorter period than the indirect effect of the net exports.

- Finally the changes in exchange rate affect nominal wages through the impact of imported middle prices in terms of national currency on the Consumer Prices Index. When these two effects are combined, the inflation rate is affected by the cost of domestic products. The second important point related to the role of the exchange rate in the inflation targeting strategy is that as an asset price, the exchange rate is a future variable and an anticipating variable. So, it contributes to the creation of expectations that have a significant place in monetary policy. The last important point is that some external problems of the exchange rate are the national economy. Fluctuations in variables such as external inflation rate or foreign interest rates 
directly affect domestic demand generated by foreign exchange rates. Similarly, Woo (1984) refers to four channels in which exchange rate influences domestic inflation.

- The prices of imported goods directly affect the consumer price index,

- The prices of imported goods directly affect the cost of domestic goods,

- The fluctuations in the exchange rate, directly affect the current account thus the total demands and the changes in the total demands are affected,

- The effect of foreign commodities on increasing prices.

In addition to the above mentioned imported cost and imported input cost channels, there is also a real balance channel. Accordingly, the devaluation will increase the prices of the goods subject to the trade compared to the goods that are not subject to the trade, which will lead to an increase in the overall level of prices. As the weight of the goods used in the consumer basket increases, the increase in the general level of prices is higher (Woo, 1984).

In economics literature, exchange rates to prices are generally defined through two channels, direct and indirect Hendry, 1980). Direct channel is associated with the concept of the law of one price and purchasing power parity. Accordingly, changes in the exchange rate for an imported good price are directly reflected in domestic prices. The indirect channel is expressed as total demand channel. The increase in the foreign exchange rate leads to the cheaper domestic goods for foreign consumers, resulting in the increase of exports and total demands and prices. The increase in the foreign exchange price raises the inflation rate. As a result of this increase, the increase in the price of imported goods increases the cost of production and inflation since these goods are either goods for consumption or intermediate goods (Agenor and Montiel, 1996). If the increases in the general level of prices are a result of an increase in the volume of money, the exchange rate will rise proportionally (other conditions, especially if the oil revenues are fixed). In this condition the increases in nominal exchange rate raises the overall level of prices. While the nominal exchange rate is rising, the real exchange rate will remain constant. But some factors, such as falling oil revenues lead to a faster rise in the exchange rate than inflation, so as the real exchange rate increases, raises the price of imported goods affects inflation, But since the real exchange rate is not constantly rising, this effect is temporary (reference).

\subsection{Empirical Studies}

Different studies have been done about the inflation and exchange rate in Iran. Liquidity growth, government spending, budget deficits, wages, inflation expectations and exchange rate were associated with inflation in these studies.

Bafekr (1998) investigated the most important factors explaining Iranian inflation. This study shows that a $10 \%$ increase in liquidity in the long run leads to an increase of $2.7 \%$ in retail sales inflation and 3.2\% in wholesale inflation. On the other hand, a 10\% increase in production reduces retail prices by $1.7 \%$ and wholesale prices by $2.4 \%$.

Dawodi (1997) examined the inflation process in Iran in three different time periods, short, medium and long term. He concludes that 1\% increase in liquidity, 95\% increase in inflation and $1 \%$ increase in exchange rate, caused inflation to rise $0.301 \%$.

Kazerouni and Asgari (2002) examined the characteristics of the Iranian economy in a theoretical framework and found a positive relationship between inflation and money 
supply growth.

Morad1 (2001) concluded that Iran's inflation determinants between 1959- 1996 were the money supply, the exchange rate in the free market and the price index of foreign currencies. In the short term, he saw that the change in oil prices had an impact on inflation.

Isfahani and Yavari (2003) included money supply increase, exchange rate increase and inflation expectation as nominal variables in a VAR model between 1971-2001; As the real variable, they have taken the real gross national product deficit. Using the VAR model, they found that inflation was affected by all these factors.

\section{Methods}

\subsection{Hendry Method}

Hendry is the closest method to classical research methods. Hendry has presented a general specific modeling method. Hendry was quite inspired by Sargan (1964) in his methodology. This method consists of 5 stages (Hendry, 1980, Pegan, 1987).

- The assumption of economic theory establishing an unconstrained general model covering the variables affecting the equilibrium relationship and reflecting the dynamics of the process as much as possible.

- The model is reparametrized to arrive at exogenous variables that can be interpreted in terms of orthogonal (independent of each other) and final balance.

- The model is simplified to the smallest version which is available.

- The predictive power of the model formed in the previous step is tested.

- The model is compared with alternative models through nested / non-nested tests and it is determined whether there is a better "rival" model in terms of statistical significance.

\subsection{VAR Model}

According to Sims, if there is true simultaneity among a set of variables, they should all be treated on an equal footing; there should not be any a priori distinction between endogenous and exogenous variables. It is in this spirit that Sims developed his VAR model (Gujarati, 2001).

In the VAR method, in the process of shaping the econometric model, the existence of a definite economic theory that is specific, affects the formation of the model which is not accepted. The constraints, assumptions, and the model theory suggested by the economic theory are not allowed to distort the model definition. There is no preliminary constraint on the relationships between variables. Thus, the negative effects of the assumptions that economists have to make in the phase of modeling are largely absent. The VAR model, is used extensively on time series in economic studies, departs from the simultaneous equations system because it does not require endogenous and exogenous. Distinct from these variables all variables in VAR are endogenous (Elgar, 1992).

The VAR model is widely used to investigate the existence and direction of inter-variable relationships (Ak1n \& Oktay, 2013). VAR models are used primarily to examine the relationship between macroeconomic variables and to examine the dynamic effect of 
random shocks on the system of variables. Relationships among variables in VAR model examined by means of Variance Decomposition and Impulse-Response functions based on Granger Causality Test. VAR modeling is quite sensitive to the selected appropriate lag length. In the VAR analysis, the delay lag of the variables that will enter to the model must be the lag that will capture the dynamic relationships between the variables. VAR models are linear functions of each variable in the system, as well as its own lagged values and the lagged values of other variables. If there is no restriction in this case, the right side of each equation in the VAR model will contain the same variables. Besides, lagged values of dependent variables in VAR models make it possible to make strong predictions for the future (Kumar, Leona, Gaskin, 1995). There are various criteria in determining lag length in VAR model. Some of these are the Akaike Information Criteria (AIC) and the Schwarz Bayesian Criteria (SBC).

\subsubsection{Impulse-response functions}

The interpretation of the coefficients estimated by VAR analysis is quite complex. For this reason, in order to interpret the results of the VAR model, a graphical representation of the responses given by the variables to the shocks, namely the impactresponse analysis, is used (Kasapoğlu, 2007). Impulse-response functions reveal the sensitivity of dependent variables in VAR model to shocks of other variables. Impulse response functions show the effects of shocks on the adjustment path of the variables. For this reason, a unit shock is applied to the error term of each variable in each equation, and the effects seen over time in the VAR system are monitored (Brooks, 2002).

\subsubsection{Variance decomposition}

Another important tool extracted from the VAR model is variance decomposition. Knowing the characteristics of predictive mistakes provides a significant benefit in revealing the interrelationships between variables in the system. The variance decomposition is defined as the decomposition ratio of the predictive error variance of each variable to the components that can be loaded into each variable in the system (Tari, 1999).

This technique shows the numerical effects of shocks on variables. The variance decomposition describes how much of the estimated error variance of a given variable after step s can be explained by the shocks observed in each independent variable $\mathrm{s}=1$, 2 ,.... In practice, it appears that a large part of the estimated error variance is usually explained by the shocks observed in the series itself. The variance decomposition indicates the amount of information each variable contributes to the other variables in the autoregression. It determines how much of the forecast error variance of each of the variables can be explained by exogenous shocks to the other variables.

\subsection{Granger Causality Test}

In the analysis of causality, it is necessary to eliminate the trends and make the variables. Granger's concept of causality is in reality a VAR model with an appropriate lag length when the causality relation between two variables is examined, they are regressed with 
each other according to the constrained regression logic with appropriate lag lengths. For each estimated regression, the $\mathrm{F}$ values are calculated using the error terms squares obtained and compared with the F table value. Xt is the unrestricted model established to find the answer to the question of $\mathrm{Yt}$ 's reason;

$$
Y_{\mathrm{t}}=\sum_{i=1}^{k} \alpha_{\mathrm{i}} Y_{\mathrm{t}-\mathrm{i}}+\sum \beta_{\mathrm{j}} X_{\mathrm{t}-\mathrm{j}}+u_{\mathrm{t}}
$$

(1)

The sum of the squares of the error terms obtained after the model's prediction is found. This value is expressed in SSRUR. Our next step is the estimate of the constrained model. Our unrestricted model for this is;

$\mathrm{H}_{0}: \beta_{\mathrm{j}}=0$ (Xt is not the cause of $\mathrm{Yt}$, the restricted model is valid).

$\mathrm{H}_{1}: \beta_{\mathrm{j}} \neq 0$ (Xt is the cause of $\mathrm{Yt}$, the unconstrained model applies).

The test statistic that needs to be calculated is water.

$$
\left.F=\frac{(S S R(R)-S S R(U R)) / m}{S S R(U R) / n-k}\right)
$$

$\mathrm{M}=$ number of constraints

$\mathrm{K}=$ Number of parameters in unconstrained model

$\mathrm{N}=$ number of samples

The H0 hypothesis is rejected if False > Ftablo. That is to say, $\mathrm{Xt}$ is the Granger of Yt, the unconstrained model is the equivalent.

\section{Economical Analysis}

In this section, two methods were used to analyze the relation between the inflation and the exchange rate of the Iranian economy, Hendry's general to specific method and VAR analysis.

Based on what was elucidated in the preceding sections, in line with the objectives of the study, the following research question is posed:

RQ1: Is there any relationship between exchange rates and inflation in the Iranian economy.

In the analyzes, time series data belonging to the Iranian economy were used. To apply the Hendry method, annual data for the period 1976-2012 were used and these data were taken from the World Bank (WB) publications. In the VAR analysis, the data are quarterly annual data for 1997: 3-2011: 4, taken from the Central Bank of Iran (CBI) and Iranian customs annual reports. The Eviews 7 package program is used to estimate the models.

\subsection{Hendry Method}

This study investigated the relationship between exchange rate and inflation. For this purpose, the following model was established.

Inf $=\alpha+\beta \mathrm{dk}+\mathrm{u}$

Here, inf; Inflation rate (annual percentage increase in consumer price inflation) dk; Exchange rate (real effect exchange rate index $(2005=100)$. Our economic expectation will increase the inflation rate when the exchange rate increases. Stability tests were done before the model predicted. In this study, the ADF (Argumented Dikey Fuller) test was 
used to test whether the data contains unit root. The results are given in table 1.

Table 1: Stationary Test Results (1976-2012)

\begin{tabular}{ccc}
\hline Variables & ADF(Drift and trend) & Critical Values \\
\hline Exchange Rate & -4.571255 & -3.548490 \\
\hline Inflation & -4.114554 & -3.544284 \\
\hline
\end{tabular}

Note: Critical values indicate a level of significance of $5 \%$. Values are t-statistic

As Table 1 shows, both inflation and exchange rate are stationary. The Hendry's General model is defined as the Autoregressive Distributed Lag (ARDL) and is represented as follows:

$\dot{\mathrm{Inf}}=\mathrm{f}\left(\sum_{l=1}^{\sum_{l-k} i n f}, \sum_{i=0}^{k} d k{ }_{\mathrm{t}-\mathrm{k}}\right)$

Given that economic units normally operate in a dynamic framework, it is necessary to include the lag of the relevant variables within the explanatory variable set. AIC (Akaike Information Criteria) was used to determine the number of delays and the number of delays was found to be 6 .

(5) numbered model was estimated and the following results were found.

Table 2: Estimated General Model Results

\begin{tabular}{ccc}
\hline Variables & Coefficient & $\mathrm{t}$ values \\
\hline Inf $_{\mathrm{t}-1}$ & 0.550114 & 2.923150 \\
\hline Inf $_{\mathrm{t}-2}$ & 0.701758 & -3.190061 \\
\hline$\dot{I n f}_{\mathrm{t}-3}$ & 0.532910 & 2.321296 \\
\hline$\dot{I n f}_{\mathrm{t}-4}$ & -0.240133 & 1.049655 \\
\hline$\dot{I n f}_{\mathrm{t}-5}$ & 0.119936 & 0.595592 \\
\hline$\dot{\mathrm{Inf}}_{\mathrm{t}-6}$ & -0.162608 & -0.999715 \\
\hline $\mathrm{dk}_{\mathrm{t}}$ & 0.035055 & 1.793087 \\
\hline $\mathrm{dk}_{\mathrm{t}-1}$ & -0.017112 & 0.554583 \\
\hline $\mathrm{dk}_{\mathrm{t}-2}$ & -0.022079 & 0.652398 \\
\hline $\mathrm{dk}_{\mathrm{t}-3}$ & -0.028295 & 0.848130 \\
\hline $\mathrm{dk}_{\mathrm{t}-4}$ & 0.037740 & 1.356881 \\
\hline $\mathrm{dk}_{\mathrm{t}-5}$ & -0.052005 & 1.96589 \\
\hline $\mathrm{dk}_{\mathrm{t}-6}$ & 0.064568 & 3.514869 \\
\hline $\mathrm{Sabit}_{\mathrm{dw}=2.842635}$ & 14.04950 & 2.511722 \\
\hline & $\mathrm{F}=4.354307$ & $\mathrm{R}^{2}=0.76$ \\
\hline
\end{tabular}

In Table 2, the parameters of the variables were evaluated from the economic point of view and statistically significant. Variables that are statistically insignificant and unsuitable for anticipation are excluded from the model. Restricted F test was applied in the next model transition from a general model.

Table 2 shows the results of the general model. After the general model, each constrained model is expressed as model 2 , model 3.

In general model, it is tried 2 restricted models to reach specific models. The best specific model is shown in Table 3. 
Table 3: Estimated Specific Model Results

\begin{tabular}{lcr} 
Variables & Coefficient & $\mathrm{t}$ Values \\
\hline Inf $_{\mathrm{t}-1}$ & 0.593531 & 3.695246 \\
\hline Inf $_{\mathrm{t}-2}$ & -0.486959 & 2.706585 \\
\hline Inf $_{\mathrm{t}-3}$ & 0.313404 & 1.957851 \\
\hline $\mathrm{dk}_{\mathrm{t}}$ & 0.040956 & 2.321012 \\
\hline $\mathrm{dk}_{\mathrm{t}-1}$ & -0.051089 & -2.87148 \\
\hline $\mathrm{dk}_{\mathrm{t}-6}$ & 0.027890 & 3.557826 \\
\hline Sabit & 7.759771 & 1.784482 \\
\hline $\mathrm{dw}=2.409225$ & $\mathrm{~F}_{\mathrm{kstt}}=1.15$ & $\mathrm{~F}=6.62$ \\
& & ARCH=0.09 \\
\hline
\end{tabular}

As seen in Table 3, inflation is affected by its own one, two and three lagged values. This situation emphasizes the importance of inflationary expectations in the Iranian economy. When the exchange rate in the $\mathrm{t}$ period increases, the inflation rate increases by $0.04 \%$. It can be seen that the exchange rate of the previous and the six-term period previous to the $t$ period are also influential on inflation.

All coefficients are statistically significant. R2 is high, F value is significant. The DurbinWatson value is 2.40 , there is no autocorrelation problem. ARCH value is 0.09 , there is no variance and autocorrelation problem in the model.

\subsection{VAR Model}

In this study, while the inflation-exchange rate relationship was examined, the effect of money supply on inflation was sought and VAR analysis was made using inflation, exchange rate and money supply variables. The logarithmic values of the variables were used in the analysis. In our study, stationarity analysis was performed to determine whether the values of the three variables were stationary. For this purpose, the series were examined by Arugmented Dickey-Fuller (ADF) test. ADF test results are given in Table 4.

Table 4: Stationary test results (1997:3-2011:4)

\begin{tabular}{ccc} 
Variables & ADF (drift and trend) & Critical Values \\
\hline Inflation Logarithm (linf2005) & -4.296494 & -3.496960 \\
\hline Exchange Rate Logarithm (ler) & -5.820751 & -3.506374 \\
\hline
\end{tabular}

Note: Critical values indicate a level of significance of $5 \%$. Values are t-statistic.

As can be seen from Table 4, all variables are stable at level. The optimum lag length should be determined when VAR analysis is performed. In this study, AIC (akaike information criteria) and SIC (schwartz information criteria) were taken into consideration and the number of lag was 5. Variables in the VAR model must be set endogenously and exogenously. Economic relations can be so complex that endogenous and exogenous discrimination of variables may not be possible. For this reason, Granger (1969) developed the Granger causality test to investigate causality relationships between variables.

The test for determining the direction and lag between variables in the system is called the Granger causality test. The aim is to determine whether there are two-way 
(reciprocal) or one-way relationships between more than one variable in the model (Bozkurt). Granger-causality tests were used for the estimation of the VAR model, and the results obtained for the causality relation are given in Figure.1.

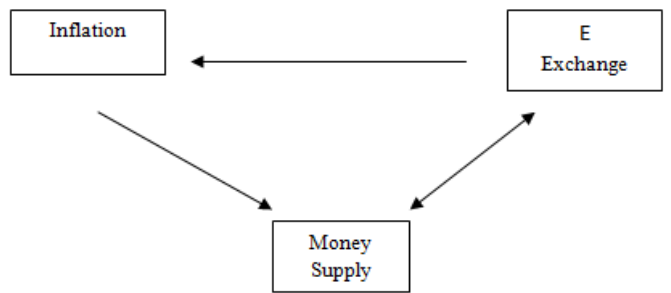

Figure 1: Causality between Exchange Rate, Inflation and Money Supply

As it can be seen in Figure 1, there is causality both from exchange rate and money supply to inflation. Ranking was realized as money supply, exchange rate and inflation. Five lagged VAR model was estimated. Taking advantage of these models, impactresponse functions were first looked at in the VAR analysis.

b. Response of inflation to one standard deviation shock of money supply

Response of LINF 2005 to LM2

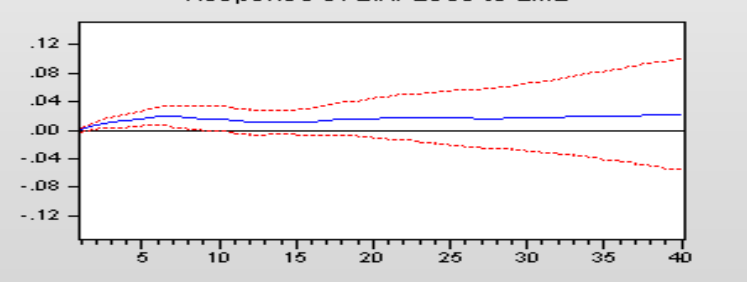

c. Response of inflation to one standard deviation shock of exchange rate

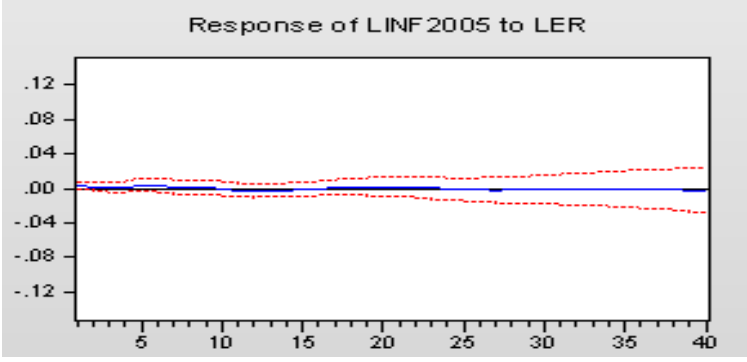

d. Response of inflation to one standard deviation shock of inflation

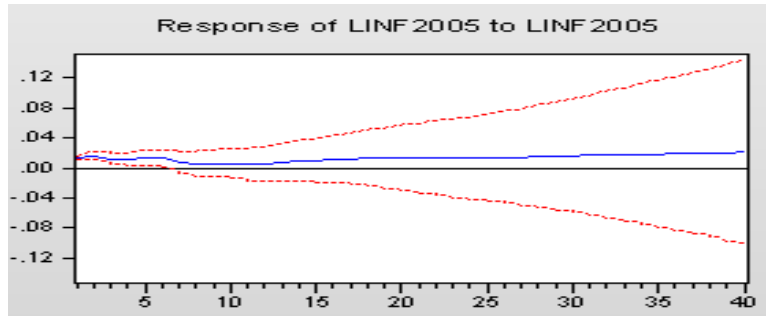

Figure 2. Impulse-Response analysis 
Considering the impact-response graphs, inflation is reacting positively during the 40th period when a standard deviation shock is given to inflation, which means that inflationary expectations are important here (Figure 2.c).

To a standard deviation of exchange rate, inflation shows a positive response and approaches the balance. Therefore, exchange rate is an effective variable on inflation (Figure 2.b).

On the other hand, inflation seems to be sensitive to money supply and has a positive response (Figure 2.a).

The variance decomposition obtained from the estimated VAR system for exchange rate, money supply and inflation relation is given in Table 5 .

Table 5: Variance decomposition of the inflation

\begin{tabular}{cccc} 
Period & Money Supply & Exchange Rate & Inflation \\
\hline 1 & 0.008870 & 3.211922 & 96.77921 \\
\hline 2 & 8.449334 & 1.913323 & 89.63734 \\
\hline 3 & 20.90819 & 1.434919 & 77.65689 \\
\hline 4 & 30.59496 & 1.078892 & 68.32615 \\
\hline 5 & 38.28967 & 1.661835 & 60.04849 \\
\hline 6 & 46.54466 & 1.827466 & 51.62787 \\
\hline 7 & 53.30462 & 1.588569 & 45.10681 \\
\hline 8 & 57.98249 & 1.442765 & 40.57475 \\
\hline 9 & 60.86721 & 1.303579 & 37.82921 \\
\hline 10 & 63.10417 & 1.245892 & 35.64994 \\
\hline 11 & 64.43089 & 1.351776 & 34.21733 \\
\hline 12 & 64.94326 & 1.538449 & 33.51829 \\
\hline 13 & 64.91120 & 1.658590 & 33.43021 \\
\hline 14 & 64.62752 & 1.683129 & 33.68935 \\
\hline 15 & 64.20485 & 1.658306 & 34.13685 \\
\hline 16 & 63.59235 & 1.568055 & 34.83960 \\
17 & 62.88241 & 1.477857 & 35.63973 \\
\hline 18 & 62.41980 & 1.407708 & 36.17249 \\
\hline 19 & 62.20982 & 1.371951 & 36.41823 \\
\hline 20 & 62.11605 & 1.338414 & 36.54553
\end{tabular}

As a result of the variance decomposition, the contribution of money supply to inflation in the second period was $8 \%$, while it was $63 \%$ in the tenth period and $62 \%$ in the twentieth period. While the contribution of the foreign exchange rate to the inflation rate is $1 \%$ in the second period, it continues in the same manner in the second and twentieth period. The contribution of the inflation in itself is $89 \%$ in the second period and it is $36 \%$ in the twentieth period. Therefore, money supply is the variable which has the largest contribution to inflation in Iran economy.

\section{Conclusion and Recommendation}

The purpose of this study was to investigate the relationship between exchange rate and inflation in the Iranian Economy. For this purpose, the relationship between 
exchange rate and inflation has been researched using the VAR method and Hendry 's General to specific modeling method. To this end, the 1976-2012 annual data was used in the Hendry method. To estimate the VAR model, quarterly annual data between, 1997: 3 - 2011: 4 was used.

According to the results of the Hendry method, inflation was affected by its own one, two and three lagged values. This situation emphasizes the importance of inflationary expectations in the Iranian economy. As the exchange rate in the period t increases, the inflation rate increases. It can be seen that the exchange rate of the one period and six periods previous to t-period was also influential on inflation.

For the VAR analysis, the money supply variable was included in the model and the effects of both the money supply and the exchange rate on inflation were investigated. According to the analysis, both the money supply and the exchange rate affect inflation positively. As a result of the variance decomposition, the contribution of money supply to inflation in the twentieth period is $62.11 \%$; the contribution of the exchange rate in inflation is $1.33 \%$ in the same period and the contribution of the inflation itself is $36.54 \%$ in the twentieth period. Therefore, the money supply variable, is the largest factor in inflation in the Iranian economy and then the inflation itself the and finally the exchange rate. For this reason, a tight monetary policy is needed to reduce inflation.

The results of the current study are in line with the works of, Bafekr (1998), Dawodi (1997) and Kazerouni and Asgari (2002) which show that there is a positive relationship between mony supply and inflation rate.

The results of the analysis of this study and many other studies in the literature emphasize that inflation is a monetary phenomenon in the Iranian economy. Therefore, the central bank should control the money supply to a degree that does not cause economic depression, since the liquidity increases is the main reason for inflation. Since inflation is affected by exchange rates and inflationary expectations, the Central Bank must be transparent in the application of foreign exchange policy, thus avoiding the inflation stems from inflationary expectations and protecting the exchange rate from excessive fluctuations by means of a more managed exchange rate policy.

\section{References}

Agenor, P.R., and Montiel, P.J. (1996) Development macroeconomics. (third edition). Princeton University Press, 215.

Bafekr, A. (1998). Investigation about causes of inflation in Iran with cointegration method. Econom Department of Shabid Beheshti University, 1-37.

Brooks, C. (2002). Introductory econometrics for finance, Cambridge: Cambridge University Press, 340-341.

Dawoodi, P. (1997). Economic stabilization policy and estimating dynamic inflation model in Iran. Research publication and economic policy. Tehran, Iran.

Dornbusch, R. (1976 ). Expectations and exchange rate Dynamics. The Journal of Political Economy, 84( 6), 1161-1176.

Gujarati, D. (2001). Temel ekonometri. (2). İstanbul: literatür yayınları, 711-841.

Hendry, D.F. (1980). Predictive failure and econometricsmodelling in Macro-ekonomics: the transactions demand for Money. Modemng the Economy, London: Heinemann Educational Books.

İran Country Overview, World Bank. (2013). Web: http://www.worldbank.org/.about/countryclassifications/country-and lendinggroups), 5 Şubat 2014' te alınmıştır.

İsfahani, R. ve Yavari, K. (2003). Refahiyete İran dar tavarrom: VAR, Feslnameye Pejuheşhaye İktisati, (16), 6999. 
Moradi, M. (2002). Nonlinear modeling of inflation in Iran. Web:www. sitecomode.net. adrsinden 01 Ekim 2014' te alınmıştır.

Pegan, A. R. (1987), Three econometric methodologies : a critica! appraisal, Journal of Economic Surveys, .(1),6.

Svensson, L.E.O. (2000). Open-economy inflation targeting. Journal of International Economics.( 50 ),155-183.

Tar1, R. (1999). Ekonometry. (2).İstanbul: Umuttepe Yayinevi, 453.

Woo, W.T. (1984). Exchange rates and the prices of nonfood nonfuel products. Brooking Papers On Ekonomic Activity. 2, 511-530.

Yurdakul, F. (1996). Ekonometride Yeni Eüilimler: Hendry ve Sims Yöntemleri- -Döviz Kuru Üzerine Bir Uygulama. Gazi Üniversitesi, Sosyal Bilimler Enstitüsü, Ekonometri Bölümü, Ankara. (Yayınlanmamış Doktora Tezi). 